\title{
THE CONSERVATION OF THE SMALL CLOISTER OF SANT'AGOSTINO IN BERGAMO: THE SURVEY OF THE TOMBS AND THE EPIGRAPHS
}

\author{
A. Cardaci ${ }^{1}$, A. Versaci ${ }^{2}$, P. Azzola ${ }^{1}$
}

${ }^{1}$ Department of Engineering and Applied Sciences, University of Bergamo, Italy - (alessio.cardaci, pietro.azzola)@unibg.it
${ }^{2}$ Faculty of Engineering and Architecture, University of Enna 'Kore', Enna, Italy - antonella.versaci@unikore.it

\section{Commission II}

KEY WORDS: 3D survey, 3D modelling, RTI tecnique, Archeology, Conservation.

\begin{abstract}
:
The restoration of the small cloister of the former monastery of Sant'Agostino, located in the upper town of Bergamo is the last act of the redevelopment of this important monumental site. During the work, several graves were found underground. The stone slabs that covered them show fragments of epigraphs allowing to date the structures for a period from the $14^{\text {th }}$ to the $15^{\text {th }}$ centuries which needed to be deepened. A knowledge project, specifically intended for the interpretation of the inscriptions was then initiated. To this end, an experiment was carried out, aiming to compare RTI photography and digital photogrammetry combined with the use of grazing light.
\end{abstract}

\section{INTRODUCTION}

The restoration of the small cloister of the former monastery of Sant'Agostino, located in the Piazzale della Fara, upper town of Bergamo, is the last act of the redevelopment of the important monumental building. The church - begun in 1290 by the order of the Hermit Friars of Saint Augustine and renovated following a fire in the years 1446-1470 by the Augustinians - and the adjoining convent had been spared from demolition, during the construction of the so-called Venetian Walls. In 1797, after the suppression of monastic orders and the establishment of the Cisalpine Republic, it was nonetheless transformed into a barracks. Although already in the 1930s a more suitable function had been envisaged by the restorer Luigi Angelini, the whole complex was delivered from the thankless military function only many decades later, when it was acquired by the Municipality of Bergamo and finally entrusted to the local University (Cardaci et al., 2019). Conservation activities began in 2014 and first involved the large cloister with the chapter house and, several years later, the church which was converted into a large conference hall (figs. 1,2). The minor cloister, with adjoining bodies, was long abandoned and unused. It is only in recent years, thanks to the close cooperation between the Municipality and the University, that the recovery and reuse of the missing part has started.
The building site has unearthed new treasures. The removal of the ground of the cloister has in fact brought to light several burials (figs. 3, 4). Their discovery was like a leap in time, allowing a new comprehension of the architectural evolution of the building. The tombs, systematically organized according to walls parallel to each other and perpendicular to the sides of the convent, were covered with stone slabs and, in some cases, with small brick vaults. They still present fragments of some epigraphs that make it possible to date the structures to a period between the $14^{\text {th }}$ and $15^{\text {th }}$ century. The dimensions suggest that they did belong to illustrious families and were long used over time. The most ancient, in fact, were not emptied; remains were not transferred to the ossuaries but simply 'reduced' in the same burial at the time of a new deposition.

The discovery was not very surprising, not only for the devotional character of this custom which is also documented in the same church, but also because the most important covering headstones of the present tombs had been removed to be 'saved' in 1881. At the initiative of the famous historian Antonio Tiraboschi, they were moved to the wall of the staircase leading to the main room of the Palazzo della Ragione (also called Palazzo Vecchio). In addition, a part of the epigraphs and the carved stone elements were still visible because they were embedded in the wall that supports the columns of the small cloister, on the east

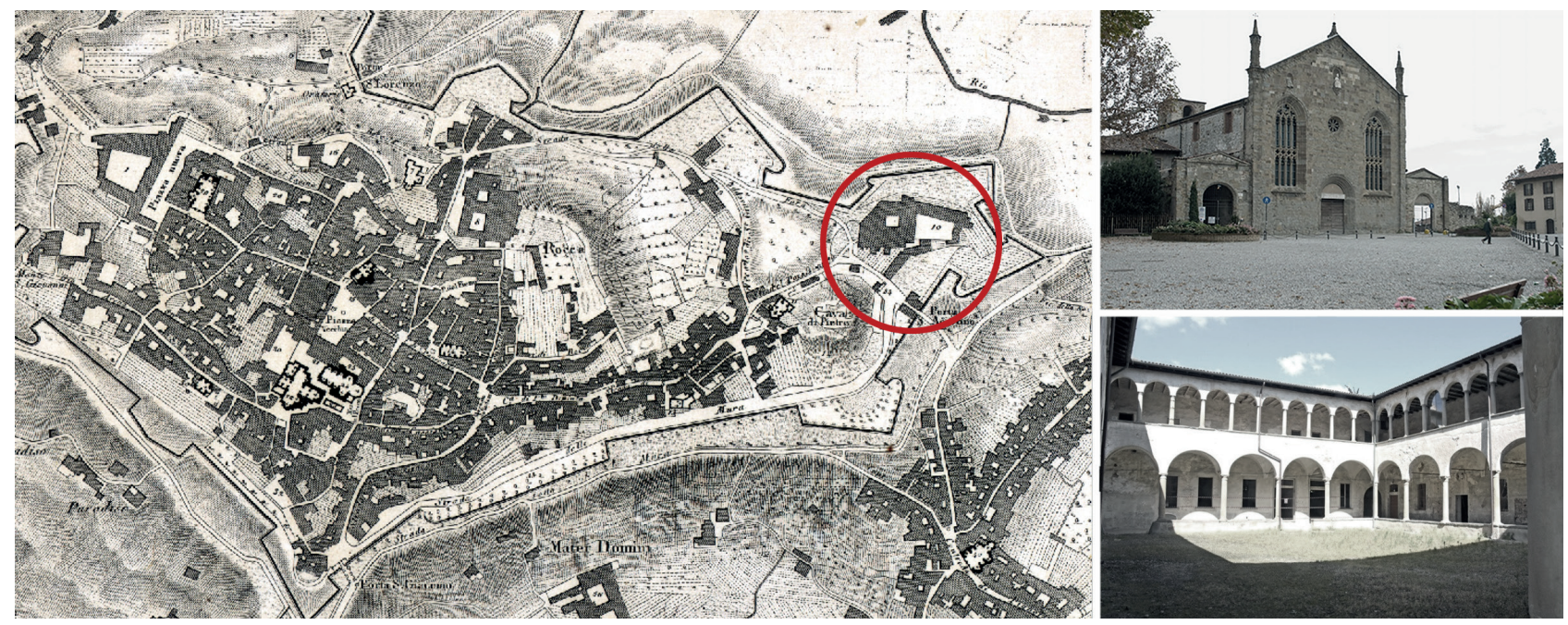

Figure 1. On the left, the monumental architectural structure of Sant'Agostino in the first scientific map of the city of Bergamo drawn up by the engineer and architect Giuseppe Manzini in 1816. On the right, the church and the small cloister before the restoration (@University of Bergamo). 

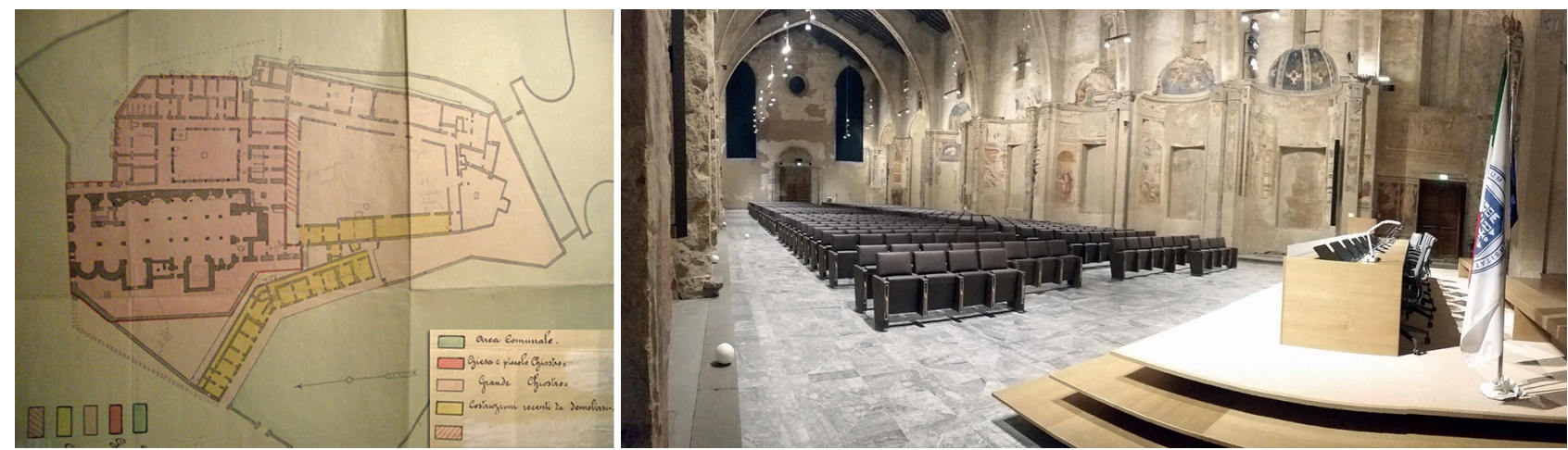

Figure 2. On the left, hypothesis of reuse of the architectural structure from a barracks to a diocesan museum studied by the engineer Luigi Angelini in 1939 (@ Archivio Diocesano, Bergamo) and on the right, the church now transformed into the Aula Magna of the University of Bergamo (@authors).

side in front of what must have been the Chapter Hall and on the south side along the wall of the church nave. They consist either of simple engraved stone slabs or architectural elements with delicate arch motifs, trilobate in shape, some of which with a small bas-relief inside that surmount entablatures bearing inscriptions, made better legible by the removal of the floor that hid and partially protected them. The discovery opened up to new scenarios of historical, architectural and archaeological interest, answering a number of old questions. The different geometry and the various typologies of the rows of the burials - some ruined by time and/or subsequent actions but others still well preserved are the key to the interpretation of the genius loci of a monument for many aspects still unknown.

The metrical, material and stratigraphic study of burials can be of great help in understanding the ancient monastery in its complex historical evolution of construction. The digitization and diagnostic analysis of grave goods, of exquisite workmanship, sometimes intact in their forms, can give an overall picture of the monastery in the urban and social context of the town. This initiated a knowledge project specifically designed to restore the system of graves and stone elements, functional to the interpretation of the inscriptions.

\section{RTI PHOTOGRAPHY AND DIGITAL PHOTO- GRAMMETRY FOR EPIGRAPHS ANALYSIS}

A beam of light splits when hits the surface of an artefact: it is partly absorbed, partly transmitted, and partly reflected. Objects are characterized by their surface irregularity and reflect light in a non-uniform manner in several directions.

They are then made up of zones with different reflectance values linked to both the surface roughness and the position and intensity of the light source. If the light source is orthogonal to the surface, the latter will be uniformly illuminated. However, if the light bundles are parallel to it, so with the light grazing, microzones of shadow will be created and reveal the texture and roughness of the surface (Mytum \& Peterson, 2018).

The use of 'grazing light' is the best solution to highlight the fine incisions chiseled by carvers on the surface of the stone. Grooves of a few millimeters depth, become visible thanks to the shadows on the edges. The use of simple straightened images, incorporated into RTI photography, is still the most widely used system for studying and interpreting epigraphs. The picture processsed by RTI allows to reveal details, which are invisible to an, even close, direct observation or in normal photos. In the archaeological field, it ensures better visibility of both figures and cuneiform characters. It can therefore facilitate the interpretation of both texts and representations, and provide additional information on the techniques of both engraving and support's preparations (Mathys et al., 2013; Fiorini, 2018).

The RTI (Reflection Transformation Imaging) processing can enhance morphological irregularities through both the value and the direction of the surface normal, calculated through the variation of reflected light in different conditions. The first algorithm developed by Hewlett Packard Labs ${ }^{\circledR}$ PTM (Polynomial Texture Map) dates from the beginning of the new millennium. A few years later, the Santa Cruz University of California with the Cultural Heritage Imaging Foundation improved the old code with the new $\mathrm{CHI}{ }^{\circledR}$ HHM (Hemispherical Harmonics Map) algori-

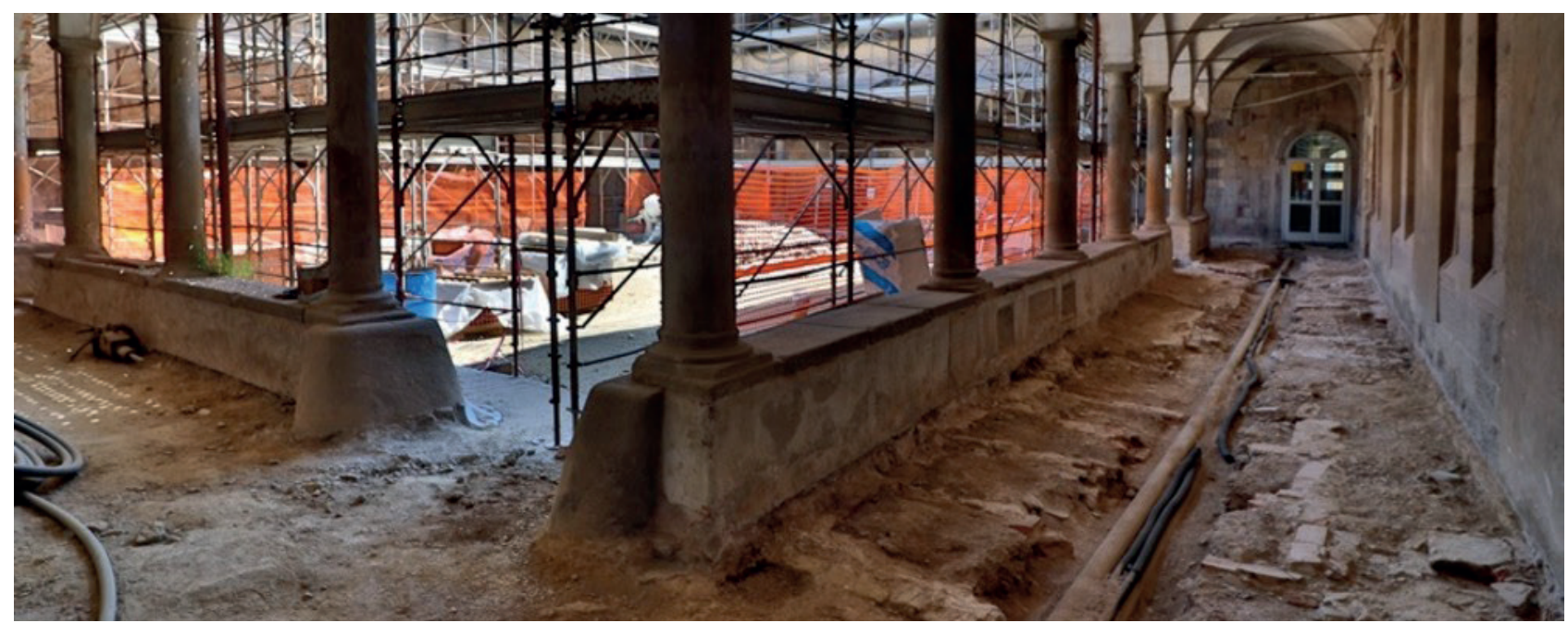

Figure 3. The building site of the small cloister with the tombs and the fragments of epigraphs (CColleoni, May 2021) 
thm. Integrated within specific software, they both allow to produce images of an object (photographed from a single point of view), which are shaded according to particular contrast modes, highlighting the three-dimensionality of the external areas.

A common digital image preserves, for each single pixel, only the RGB color coordinates; a RTI image also provides the direction and intensity of the vector orthogonal to the surface, simply called 'normal'. A RTI image, in addition to 2D visualization, offers a three-dimensional representation of objects. It is an "interactive and re-illuminable photograph" able to vary its shading depending on the position taken by the virtual light source. The spatiality of the object is perceived by the human brain not for the movement of the model, but thanks to the variation of the position and intensity of the illuminant. In an RTI image, the geometry is very accentuated because it is displayed by rendering algorithms that use both the RGB information of the pixel and the information of normal vectors. The reproduced plot does not correspond to the real shape of the object because the 'normal vector' is not calculated based on the spatial position of the image points, but by a software processing linked to the shadows of the scene. A not rigorous - sometimes imprecise - method that still creates the illusion of roughness and can highlight the characteristics of surfaces that are not detectable by direct observation.

A RTI document cannot reconstruct a three-dimensional model; this is only possible with digital photogrammetry. However, the normal image-based 3D modeling do not provide the same quality as the rendering of RTI images. To obtain it, it is therefore necessary to optimize the photogrammetric process, both with a careful planning of the photographic captures and the definition of a workflow dedicated to data processing.

The photographic campaign must be designed with two different capture families: a first series of shots with the camera facing the center of the object and a second series with close-in sockets from a camera parallel to the surface.

The first group of photos, similar to what happens for RTI photography, must be taken at regular intervals, with an overlap of more than $75 \%$, and always from the same distance as if rotating on a sphere. Contrary to RTI captures, in this case, it will not be the light that turns around a point (and the camera remains stationary) but the camera that moves while keeping the lighting unchanged. The scene must be illuminated by a main diffuse light to uniformly radiate the whole object and avoid shadow areas without information. It is also useful to use a secondary light, of the spot type (for example the camera flash) to increase the contrasts of the images thanks to the dark parts produced by the roughness of the surface. This second light will be changeable, because it moves with the room, and must have a much lower intensity: the SFM algorithms have their best performance when the photos are vivid in colors and with little contrast.

The second group of photographs, the close-ups, has to be made using the camera as a small drone flying over the object. They are photos, which are made parallel to the surface, with macro lenses and at a very short focusing distance, capable of allowing a magnification ratio equal to and/or greater than 1:1. In this series of shots, the secondary light, generating a system of long shadows, is especially useful for improving the roughness.

The purpose of image processing is to create an accurate and accurate template. The construction of the sparse cloud is necessary to be performed several times: the first to determine the approximate position of the cameras (external orientation), the second to optimize the calibration parameters related to the characteristics of the sensor and the distortion of the lens (internal orientation), and the third to compensate and correct the position of the cameras previously calculated in an approximate way.

The construction of the dense cloud, after a rigorous cleaning of the sparse cloud with the elimination of low quality and high
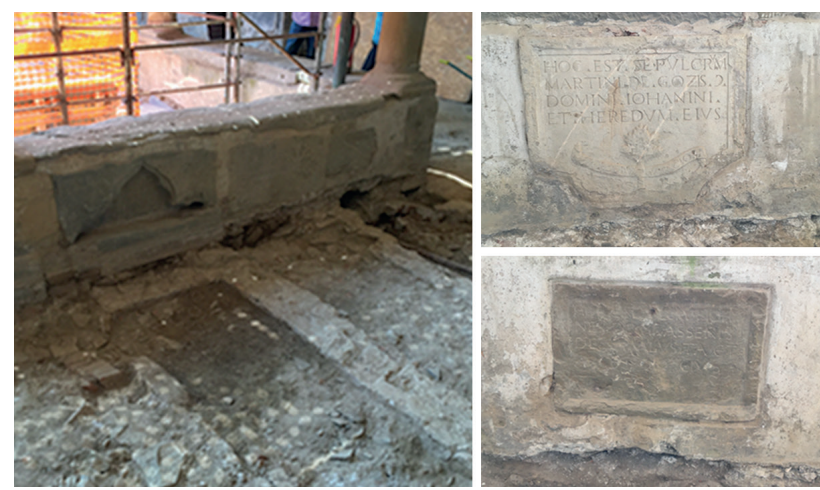

Figure 4. Details of the burial-epigraph system (@authors).

uncertainty points, must be accompanied by the verification of high confidence interval. A procedure that therefore eliminates a very high number of points, all those with a confidence interval of less than $90 \%-95 \%$, to consider only those that correspond to the real geometry of the object. This therefore requires full-frame images, correctly exposed and of great sharpness (without the 'blur' defect), with a very high overlap and a great color depth (only possible with direct processing of raw files). The subsequent creation of the RGB mapping, generally performed by simply superimposing images on the model (texturing) to increase its chromatic quality, must be strictly accompanied by the calculation of the normal value, as it happens in RTI photography (Bosco \& Minucci, 2020). The interactive visualization of the point clouds generally takes place through the construction, on each vertex, of small squares (or circles if anti-aliasing is active), containing the color information, called splats. In RGB mapping, both their arrangement and size are always constant, regardless of the shape of the object and the position of the camera. The use of normal vectors, to rotate the splats towards the outside of the surface, allows a clearer and more realistic view of the geometry of the object. An improvement in the reading is both due to the possibility of generating variable shadows based on the orientation of the faces and arbitrarily increasing (or decreasing) the vector value and/or replacing the $\mathrm{RBG}$ data with a color corresponding to the inclination and intensity. This makes it possible to visualize, in false colors, the geometry of the model allowing a clearer comprehension.

Mapping a parameter on a surface can be done by different operating techniques than simply overlaying the image on the surface. Although computationally more onerous, the techniques properly called Displacement Mapping, involve a real geometric modification of the surface based on the information contained in the 'normal map' (Guidi, 2011; Remondino, 2011). The modelling is thus enhanced because, following the construction of the model, the surface of the latter is modified and adapted. The combined use of RGB information and normal vectors enables different rendering capabilities. Graphical representations can be obtained from:

- Diffuse RGB Map: it is the most widespread rendering method, characterized by the lack of shadows and reflections, which is obtained from the single RGB mapping reprojected on the points of the cloud or on the model's faces.

- Normal Visualization: it is the rendering - monochromatic or false colors - method, which shows the orientation of the object's surface pixel by pixel; the $\mathrm{x}, \mathrm{y}$, and $\mathrm{z}$ directions of the normals on each pixel are represented respectively by the colors red, green, and blue (or from white to black) which change as the orientation of the surface changes.

- Diffuse Gain: it is a rendering method that is obtained by multiplying the intensity of the normal vector by a factor greater than 1 to increase the representation of the heights and depths on the 
surface of the subjects. It improves the perception of surface characteristics by increasing and accentuating the curvature of the object, especially in the presence of depression or deep incisions. - Specular Enhancement: it is a rendering method that is obtained from the RGB color and considers the orientation of the normal for calculating the reflectance. It, therefore, returns the diffused light component and the specular reflection derived from the shape of the surface. The imperfections of the surface are thus underlined by the specular lights and this makes the inscriptions more legible.

Their use was therefore also applied to the case study of the small cloister of Sant'Agostino after verifying, in the laboratory, the optimal procedure for taking pictures in a condition of mixed lighting, both natural and artificial (fig. 5).

\section{LABORATORY TESTS}

The survey of the epigraphs, aimed at highlighting the traces of the chisels on the surfaces, was then performed with digital photogrammetry and with the support of RTI photography. The need to define an optimum procedure and to verify the efficacy of the two methods required prior experimentation in the laboratory. The tests were made on an engraved stone element and in a controlled luminous environment. The stone element was placed in the center of the room and arranged horizontally on a rigid support so that it could be photographed/illuminated by rotating it and from different heights. A freedom of intervention that we do not always have when the graffiti belong to large and non-transportable structures (buildings or rock walls, for example), which, however, has not limited the central role of the experimentation because the results obtained guided the subsequent survey operations in Sant'Agostino.

Photo capture and RTI processing followed the operational protocol suggested by $\mathrm{CHI}$ Corporation ${ }^{\circledR}$ (Cultural Heritage Imaging), an association of scholars interested in the development of effective solutions in the field of digital imaging for the conservation of cultural heritage. The CHI Corporation $\AA$, in particular, has developed an easy-to-use operating procedure for the realization of RTI images: from the capture (through a specific tool kit) to the processing with the open-free software RTI-Builder, to the restitution interactive with the open-free RTI-Viewer software. The study and updating of algorithms has, alas, been stalled for many years, but the proposed solutions remain valid and very useful today.

The image capture process was performed with a fixed camera and mobile spotlighting. On the rigid support, on the sides of the stone element, markers (topographically measured) were placed to create a geo-referencing network. The coordinates of the vertices, four in total, were used to verify the precision of both the models and the metric processing. The camera, a Canon ${ }^{\circledR}$ EOS 5D Mark-IV, was equipped with a Canon ${ }^{\circledR} 50 \mathrm{~mm}$ f $/ 1.4$ fixed lens with low geometric distortion and great brightness.

The system was placed - using a solid stand - at a height of 185 $\mathrm{cm}$; the stone element was subsequently taken following Nadir direction. The shots were taken with a remote control - via a wireless system - to avoid vibrations and/or accidental movements. The characteristics of the sensor, the lens, and the distance from the object have allowed obtaining a high value of the GSD (Ground Sample Distance) of less than $0.2 \mathrm{~mm}$; the shots were taken semi-automatically in aperture priority mode, equal to f/10 for a hyperfocal distance of about $85 \mathrm{~cm}$ and an ISO sensitivity set at 125 . Two black, shiny, and reflective spheres $-57 \mathrm{~mm}$ in diameter - have been placed inside the grip field to know, for each shot, the direction of the incident light.

The photographic data acquisition was carried out by moving the

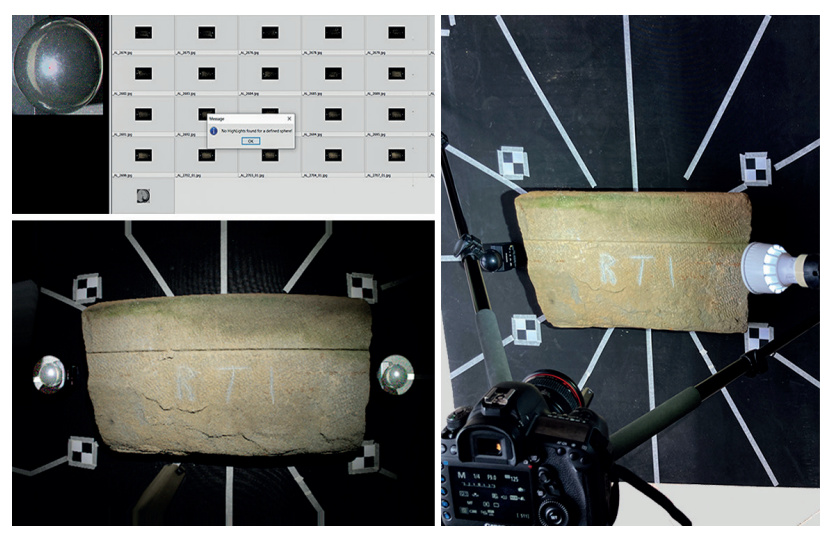

Figure 5. The photographic capture set for laboratory tests.

light spot on an ideal sphere with a radius of about two meters; 36 shots were taken from three different vertical angles $\left(15^{\circ}, 40^{\circ}\right.$, and $65^{\circ}$ ) and twelve different horizontal positions (interval of $30^{\circ}$ ). To simulate the real site condition at the former convent of Sant'Agostino, where it is not possible to eliminate the ambient light, two sets of images were performed for two subsequent RTI processing: the first one with only spot lighting and the second one with spot light and moderate intensity diffuse lighting. Both sets of photos, because of different color temperatures, were compensated and returned to ideal light condition using the X-Rite ${ }^{\circledR}$ Color Checker (figs. 6a, 6b).

In both cases, image processing was done with the Cultural Heritage Imaging (CHI)'s RTIBuilder software. The first phase was the automatic identification of the spheres and the calculation of the direction of the illuminant. This because the map of the normal vectors of the pixels takes place with an indirect calculation based on the shadows (and not on the geometry of the object as for photogrammetry). The use of several spheres - with a perfectly smooth and highly reflective surface - made it possible to evaluate the light direction in each photo with accuracy, avoiding that approximate estimates could invalidate the final result.

The natural vector map can be generated using either the PTM (Polynomial Texture Map) or HHM (Hemispherical Harmonics Map) adjustment algorithm. The PTM pipeline transforms the images into shades of gray and then merges them with the original RGB sampled again to low-resolution PPI (Pixels Per Inch). This is a treatment born in the astronomical field and known by the acronym of LRGB (Luminance, Red, Green, and Blue), which reduces the size of the files and speeds up the work but, inevitably, alters the fidelity of the colors. The HHM pipeline, on the other hand, uses RGB images without alterations, determining the value of normal vectors through polynomial equations with 4,8 , or 16 variables; a more onerous computational work which in any case leads to better results.

The authors opted for HHM processing (Earl et al., 2010; Frank et al., 2021). The rendering of the model, through the CHIC RTIViewer, was implemented with the basic mode because it can return an image similar to a normal photograph; the scene is characterized by uniform lighting, without shadows, and without particularly evident bright areas. A visualisation that allows a harmonious distribution of the surface reflection but emphasizes and clarifies the traces of graffiti (Miles et al., 2015).

The comparative evaluation of the two sets of images (with and without diffused light) highlighted a significant difference in terms of 'incisiveness', the detail of the carvings, and the hardness of the shadows. The diffuse light weakened and acted negatively on the final RTI image, considerably reducing its legibility. Subsequent tests for photogrammetric processing were done on the same stone element and in the same laboratory, with a slightly different photocapture process. The camera has been repla- 
ced by a lamp equipped with an umbrella diffuser able to create a uniform glow over the whole surface of the engraved stone. The 36 positions previously occupied by the spot, in this new phase, were instead occupied by the camera (the same as in the first experiment in order not to make changes to the GSDs) with a flash mounted on it. Three sets of images were acquired (one more than in the RTI experiment) in three different lighting conditions; the first with diffused light only, the second with only the use of the flash, the third with the combined use of both the diffuse source and the flash.

The processing followed the traditional photogrammetric workflow, from the orientation of the frames to the generation of the sparse point cloud and finally to the generation of the 3D model (dense point cloud and related triangulated meshes).

Special attention was paid to the evaluation of the metric quality of the points, as described in the previous paragraph, to have a very accurate model in the measurements and very precise in

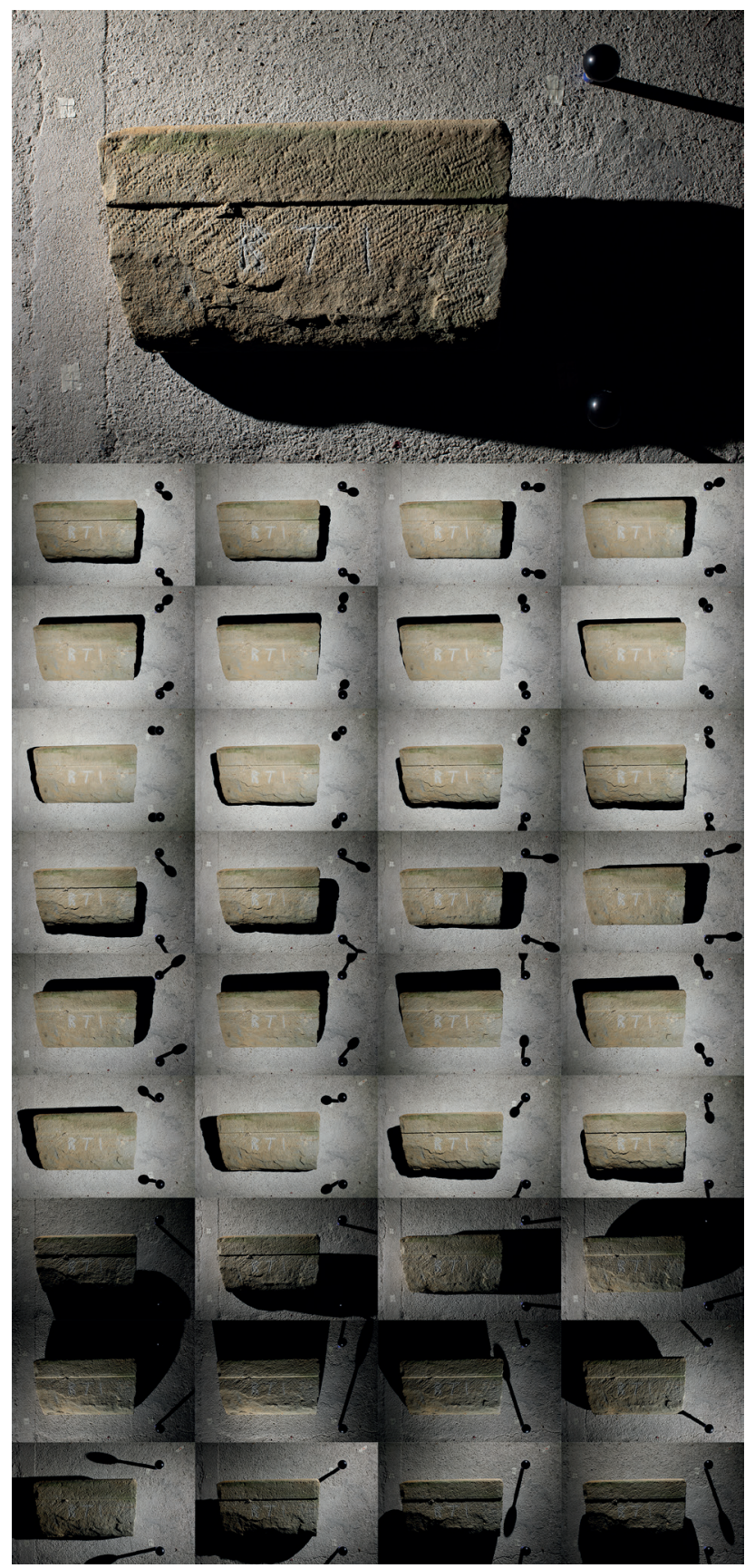

Figure 6a. RTI process: images with spot light only. the details (fig, 7). Only two models could be produced from the three series of photographs (Mathys et al., 2013; Rahaman \& Champion, 2019). The images acquired with only the flash 'bring into crisis' the SFM algorithms, without result.

The first observations made it possible to see how the addition of the flash led to an improvement in the model, limited but widespread, which made it possible to reconstruct the hollowed areas more effectively. This is very evident from the comparison of point clouds where the presence of red areas shows an emphasis on unrounded edges. It was not possible to provide a qualitative answer to the question about the interaction between main light and spot light; however, it is evident that a predominance of spot light, beyond a certain intensity, does not allow image-based 3D reconstruction software to work correctly.

The comparison of the results between digital photogrammetry and RTI photography has shown that the latter technique is only effective in special conditions that can be recreated in the

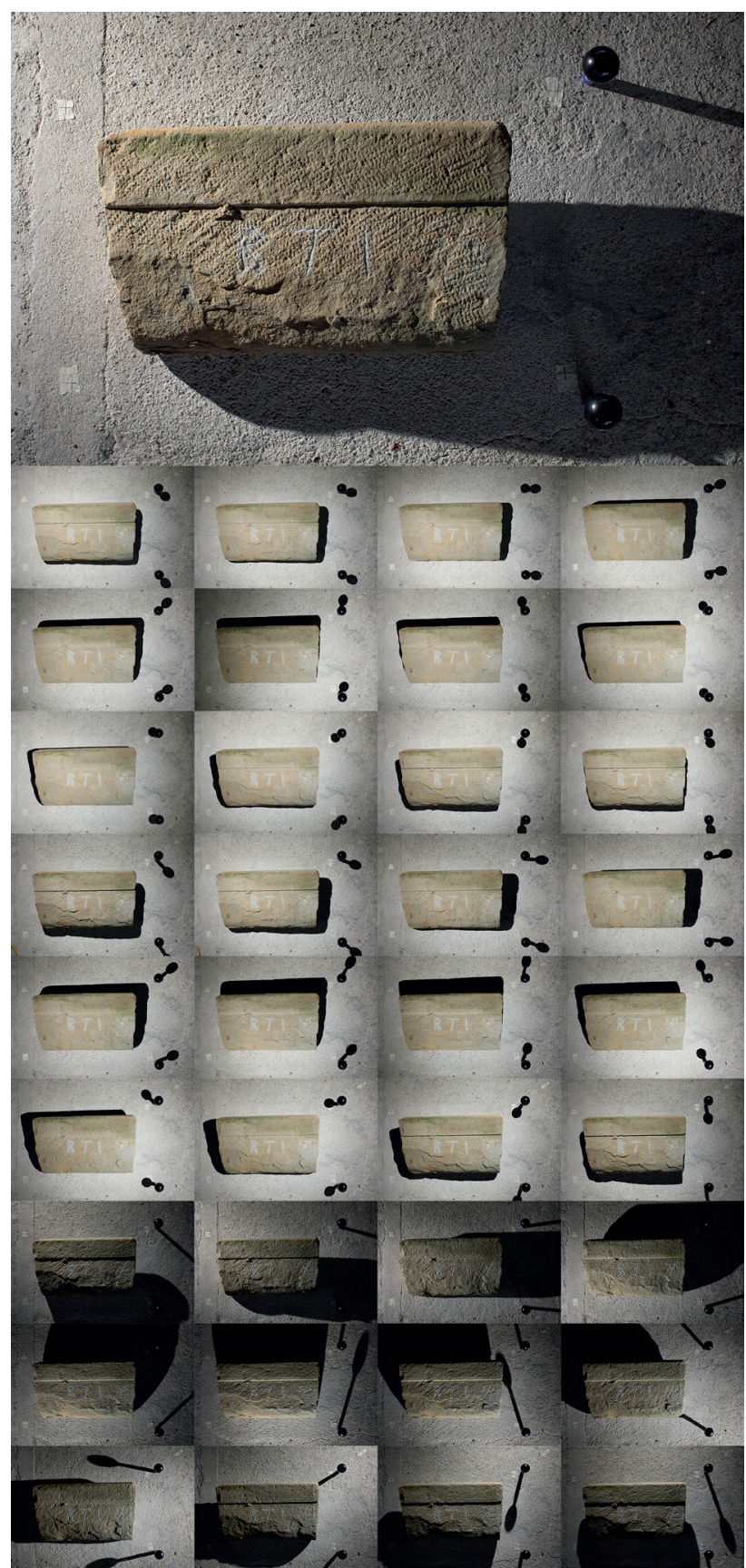

Figure $6 \mathrm{~b}$. RTI process: images with spot light and diffuse light. 

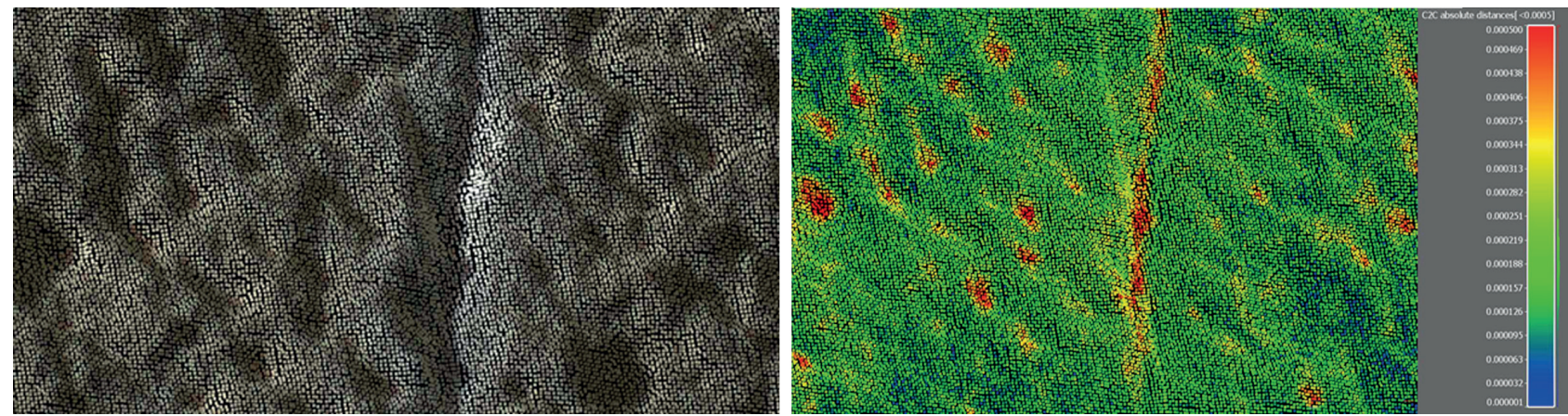

Figure 7. On the left, a detail of the points cloud by images with diffused and grazing lights. On the right, the comparison between the points cloud obtained from photos with diffuse light only and that with diffuse + grazing lights. The red areas show the best reconstruction of the excavated parts.

laboratory. Based on these assumptions, it was preferred not to use it in the context of the construction site of the small cloister of Sant'Agostino, where instead the photogrammetric workflow developed was employed (fig. 8).

\section{THE SURVEYS AND DOCUMENTATION OF ARCHAEOLOGICAL DIGS AND EPIGRAPHS}

The surveys and documentation of both the archaeological excavation and the epigraphs were carried out in several periods and using instrumentation with both active (3D laser scanner) and passive sensors (digital photogrammetry). In particular, it was necessary to carry out a first measurement campaign before the archaeological digs and a second at the end of the excavation operations, and, finally, a high-precision survey of the epigraphs and tombstones (fig. 9).

Initially, a topographic network was prepared, whose vertices coordinates - materialized with topographic nails, both on the ground for the stations and the walls for the GPC (Ground Control Points) - were determined with a total station. The solution of the hyperdetermined network equations (both for distance and angular measurements) was achieved using least squares compensation software. In this case, the well-known commercial product MicroSurvey ${ }^{\circledR}$ Star*Net was used because it can combine ease of use and essential functions with great reliability and rigour. The topographic network allowed the post-acquired point clouds to be superimposed in a single reference system and the accuracy of the overlaps to be verified. Subsequent processing was conducted in 3 phases (fig. 10).

- Phase 01 took place with the detection of the actual condition of the two wings of the small cloister involved in the presence of tombs. The global point cloud, a fusion of individual 3D laser scanner scans and photogrammetric processing, was produced with the combined use of multiple software, specifically, Faro ${ }^{\circledR}$ Scene, 3DFlow ${ }^{\circledR}$ Zephyr, and the open-source CloudCompare application. The 'certain' and reliable geometry of the 3D laser scanner and the virtual model recreated based on the various photogrammetric treatments, thus made it possible to obtain a metrically accurate discontinuous model of high chromatic quality. Photogrammetry made use of only the raw data obtained by the photographic sensor using the new WIC (Windows Imaging Component) - integrated into 3DF Zephyr - able of processing the raw sensor files while maintaining the metadata, the bit-data depth (up to 32 bits per channel) and the high-dynamic range.

- Phase 02 did not commence until the tombs were excavated. In the beginning, the Lombardy Archaeology Superintendence had hypothesized to investigate all the burials but, after the opening of the first three, it immediately became clear that during the works that occurred at the end of the $19^{\text {th }}$ century, they had been violated and deprived of their contents. It was then decided not to continue with the activities - which would, in any case, have provided archaeological material of great historical and cultural interest - also in order not to delay the activities.

The study of the entire zone was subsequently carried out again, both by 3D laser scanner and photogrammetry, using the same operating methods adopted for phase 01 (fig. 4). The second global cloud was divided into several photogrammetric patterns for the three excavated burials. The removal of each stratigraphy unit from the field has been documented to obtain partial models for each section.

- Phase 03, finally, focused on a refinement of the photogrammetric point cloud in correspondence with tombstones and epigraphs, to read the texts contained therein. The erosion phenomena and human actions have, in fact, almost cancelled the signs of the sculpted parts, evident only following a 'close' observation
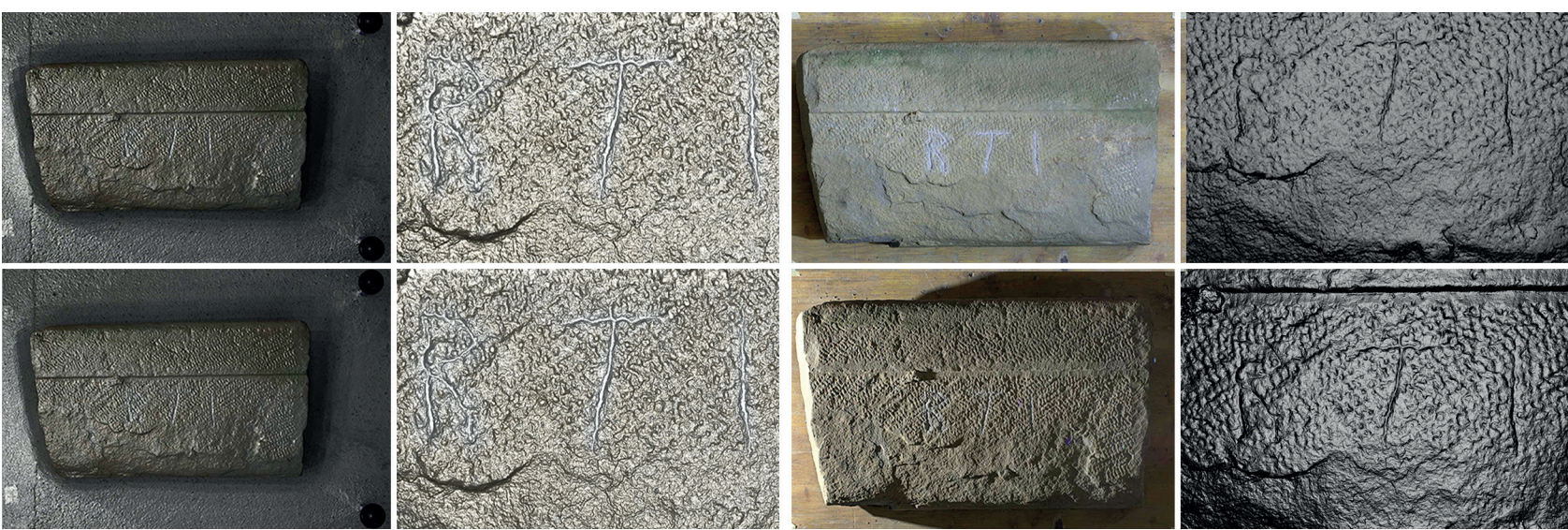

Figure 8. Laboratory tests for the best use of the RTI technique: on the left, RTI images from object illuminated with only grazing light and grazing plus diffuse light; on the right, photogrammetric 3D model made with shots taken with only diffuse light and grazing plus diffuse lights. 
(therefore with a high degree of magnification) and an illumination with grazing light. A photo campaign was then started with high-resolution full-frame cameras and macro lenses and a very short focusing distance. In addition to natural lighting, use was made of spotlight lamps arranged 'cutting' on the tombstones to have a series of shots in which the surface texture, and therefore the engravings, was more highlighted (fig. 13).

The images were then processed with both image-based 3D reconstruction applications, then acting to focus on normals, as well as reconstructing RTI images and photogrammetric models.

\section{CONCLUSIONS}

The comparison of the results between digital photogrammetry and RTI photography, applied to the study of epigraphs, showed that the latter technique is the only really useful in specific conditions that can be recreated in the laboratory. Instead, a correct photogrammetric approach combined with the use of grazing light (of low intensity in order not to interfere with the main diffused light), has shown how it is possible to obtain precise and accurate models. Models that displayed with appropriate rendering methods - able to exploit the normal vector of points and/or sides - allow the reading of millimetre details.

The photogrammetric model, in this context, has a twofold usefulness, both documentary and interpretative. In fact, it proves to be a valid tool for classifying, cataloguing, and maintaining the geometric-material memory of goods that are subject to progressive erosion and consumption. It is an important aid for the archaeologist and the epigraphist because having a database that can be interrogated with a simple viewer in different lighting conditions greatly facilitates the interpretation of the signs and the micro-stratigraphic succession.

The discovery of the tombs helped to rethink the system of the tombs and the same constructive evolution of the old monastic complex. The 3D laser scanner measurement of some burials and the analysis of their internal walls together with the stratigraphic study, made it possible to ascertain that the burials were alre-
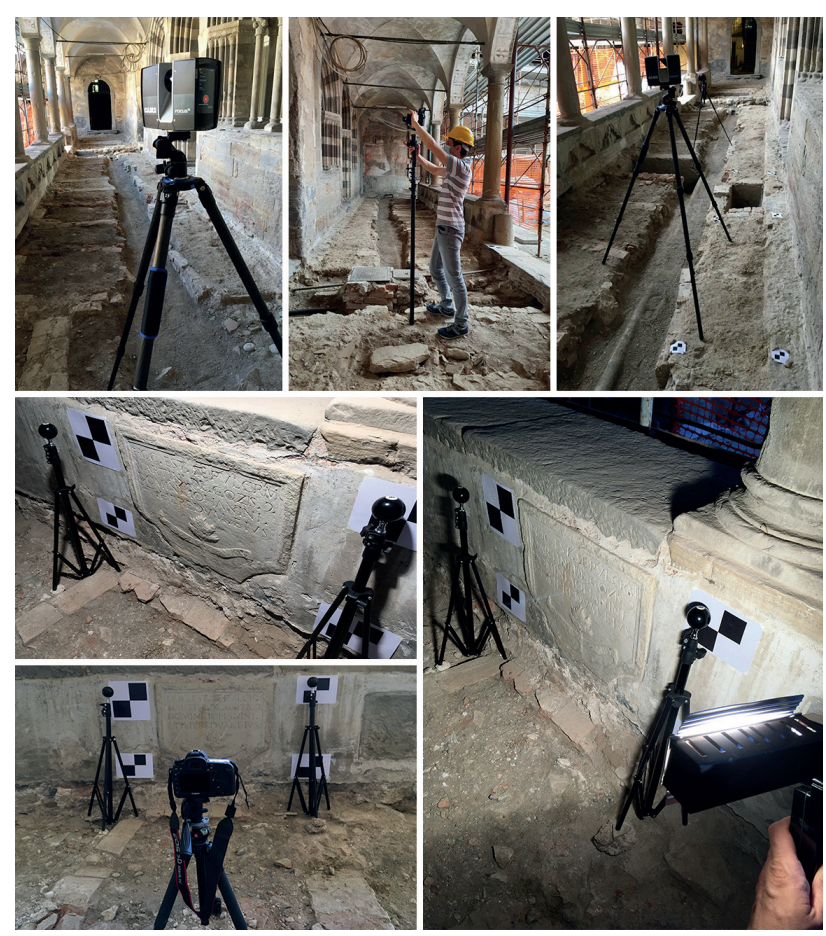

Figure 9. The survey before and after the archaeological excavations and the RTI survey of the epigraphs.

\section{THE 3D DATA ACOUISITION AND MEASUREMENT PHASES}

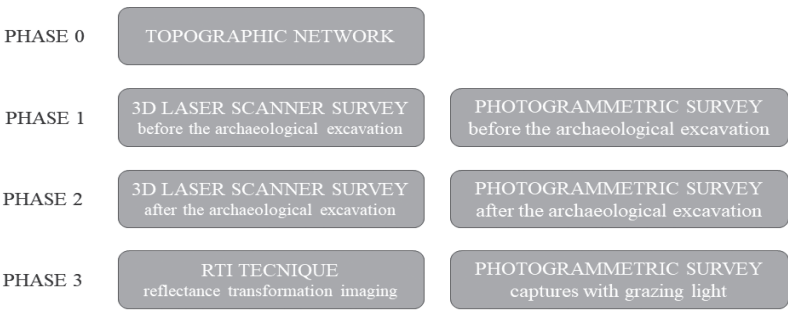

Figure 10. Workflow data acquisition and processing.
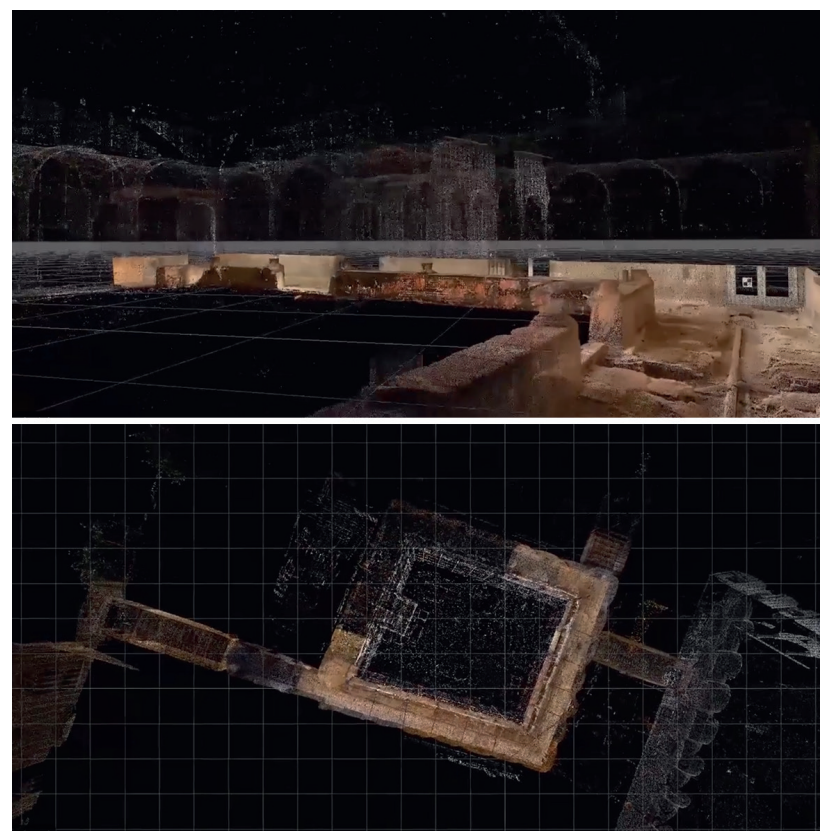

Figure 11. Phase 01: the point clouds by 3D laser scanning and digital photogrammetry (the small cloister).
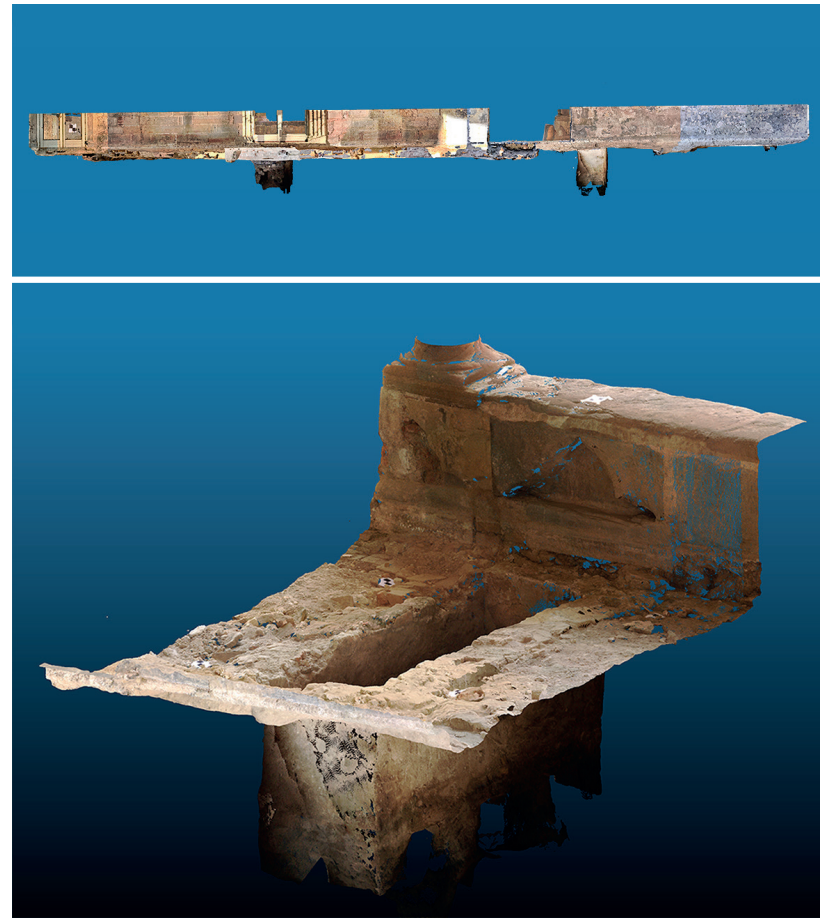

Figure 12. Phase 02: the point clouds by 3D laser scanning and digital photogrammetry (the tombs after the excavation). 


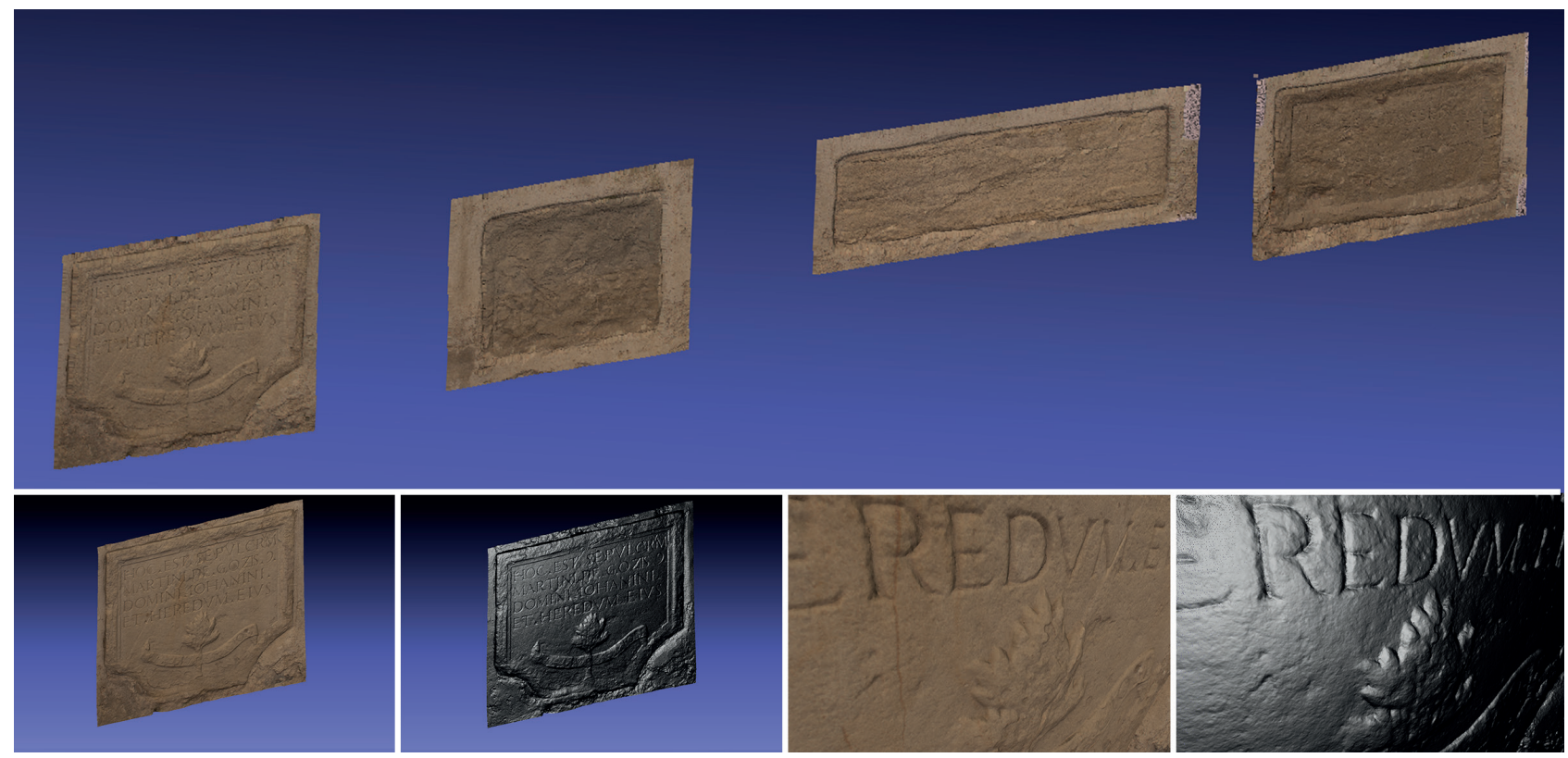

Figure 13. Phase 03: the photogrammetric models of the epigraphs: RGB (rendering with texture) and RTI (with normals visualization).

ady present before the construction of the cloister. In fact, the hypothesis that the tombstones had been placed in the low wall after construction was found to be incorrect; indeed, it is clear that the tomb system affected its geometry.

The goal of an accurate survey on a monumental building undergoing restoration should be to verify design choices especially in light of unforeseen events. The redevelopment project was designed with no awareness of the existence of a burial system and its discovery should have resulted in a variation. Unfortunately, the choice was rather to document and cover without altering the original decisions, so as to limit costs and not waste time.

In the absence of a comprehensive museum exhibition of these important discoveries, the documentation activity carried out represents, therefore, the ultimate expression of a conservative intention. If it is true that we are always interested in what we ourselves allow we are interested (Panofsky, 1962), the operations carried out may later allow to use new and different forms of analysis to deepen the study of a building bearing countless values of the history of architecture and art but also of more general values linked to other aspects of human life (Musso, 2010).

\section{REFERENCES}

Bosco, A., Minucci, E., 2020. Rendering RTI ed editing d'immagine per elaborazioni SFM: confronto tra tecniche e strumenti di visualizzazione per la documentazione di graffiti in contesto archeologico. Newsletter di Archeologia (Vol. 11), CISA, Napoli, 43-66.

Cardaci, A., Mirabella Roberti, G., Versaci, A., 2019. The integrated 3D survey for planned conservation: the former church and convent of Sant'agostino in Bergamo. Int. Arch. Photogramm. Remote Sens. Spatial Inf. Sci., XLII-2/W9, 235-242.

Earl, G., Beale, G., Martinez, K., Pagi, H., 2010. Polynomial texture mapping and related imaging technologies for the recording, analysis and presentation of archaeological materials. Int. Arch. Photogramm. Remote Sens. Spatial Inf. Sci., 38(part 5), 218-223.

Fiorini, A., 2018. Il metodo fotografico RTI (Reflectance Transformation Imaging) per la documentazione delle superfici archeologiche: l'applicazione ai materiali di età protostorica. Archeologia e Calcolatori, 29, 241-258.

Frank, E., Heath, S., Stein, C., 2021. Integration of Photogrammetry, Reflectance Transformation Imaging (RTI), and Multiband Imaging (MBI) for Visualization, Documentation, and Analysis of Archaeological and Related Materials. ISAW Papers, 21. (http://dlib.nyu.edu/awdl/isaw/isaw-papers/21/).

Guidi, G., 2011. Monumenti poligonali o poligoni monumentali?. In Il ritorno all'immagine, nuove procedure image based per il Cultural Heritage, Lulu Press, Raleigh, 4-10.

Mathys, A., Brecko, J., Semal, P., 2013. Comparing 3D digitizing technologies: what are the differences?. In 2013 Digital Heritage International Congress (DigitalHeritage), 201-204, doi: 10.1109/DigitalHeritage.2013.6743733.

Miles, J., Pitts, M., Pagi, H., Earl, G., 2015. Photogrammetry and RTI Survey of Hoa Hakananai'a Easter Island Statue. In Across Space and Time: 41st Conference on Computer Applications and Quantitative Methods in archaeology (CAA). Amsterdam Press University, Amsterdam, 144-155.

Mytum, H., Peterson, J.R., 2018. The application of Reflectance Transformation Imaging (RTI) in historical archaeology. Historical Archaeology, 52(2), 489-503.

Musso, S.F., 2010. Recupero e restauro degli edifici storici, EPC Libri, Genova.

Panofsky, E., 1962. Il significato nelle arti visive. Giulio Einaudi Editore, Torino.

Rahaman, H., Champion, E., 2019. To 3D or not 3D: choosing a photogrammetry workflow for cultural heritage groups. Heritage, 2(3), 1835-1851.

Remondino, F., Rizzi, A., Agugiaro, G., Jimenez, B., Menna, F., Nex, F., Baratti, G., 2011. Rilievi e Modellazione 3D. In $15^{a}$ Conferenza Nazionale ASITA, Ed. Asita, Milano, 1825-1836. 